NBER WORKING PAPER SERIES

\title{
THE TRADABILITY OF SERVICES: GEOGRAPHIC CONCENTRATION AND TRADE COSTS
}

\author{
Antoine Gervais \\ J. Bradford Jensen \\ Working Paper 19759 \\ http://www.nber.org/papers/w19759 \\ NATIONAL BUREAU OF ECONOMIC RESEARCH \\ 1050 Massachusetts Avenue \\ Cambridge, MA 02138 \\ December 2013
}

Jensen thanks the Sloan Foundation, the MacArthur Foundation, and the National Science Foundation (SES-0552029) for research support. Gervais thanks the Institute for Scholarship in the Liberal Arts for research support. We thank James Anderson, Andrew Bernard, Lorenzo Caliendo, Robert Feenstra, Joseph Kaboski, Dennis Quinn, Stephen Redding, David Richardson, Peter Schott, Jeff Thurk, and Stephen Yeaple, as well as participants at various seminars and conferences for their comments. Special thanks to Jim Davis for timely help when it counted. All remaining errors are our own. The research in this paper was conducted while the authors were Special Sworn Status researchers of the U.S. Census Bureau at the Center for Economic Studies. Any opinions and conclusions expressed herein are those of the authors and do not necessarily represent the views of the U.S. Census Bureau. All results have been reviewed to ensure that no confidential information is disclosed. Previous versions of this paper were circulated under the title "Are Services Tradable? Evidence from US Microdata." The views expressed herein are those of the authors and do not necessarily reflect the views of the National Bureau of Economic Research.

NBER working papers are circulated for discussion and comment purposes. They have not been peerreviewed or been subject to the review by the NBER Board of Directors that accompanies official NBER publications.

(C) 2013 by Antoine Gervais and J. Bradford Jensen. All rights reserved. Short sections of text, not to exceed two paragraphs, may be quoted without explicit permission provided that full credit, including (C) notice, is given to the source. 
The Tradability of Services: Geographic Concentration and Trade Costs

Antoine Gervais and J. Bradford Jensen

NBER Working Paper No. 19759

December 2013, Revised June 2015

JEL No. F1

\begin{abstract}
$\underline{\text { ABSTRACT }}$
In this paper, we use a unique dataset on the distribution of output and demand across regions of the United States to estimate trade costs for 969 service and manufacturing industries. Our estimation method is a natural extension of the gravity model of trade and identifies trade costs in the absence of trade data. The estimated trade costs are higher on average for service industries, but there is considerable variation across industries within sectors. Using the trade cost estimates, we classify industries into tradable and non-tradable categories. We find that accounting for tradable service industries nearly doubles the international exposure of the US economy, tradable services value added is unevenly distributed across geographical regions, labor productivity and wages are higher on average for tradable industries, and potential welfare gains from trade liberalization in the service sector are sizable.
\end{abstract}

\title{
Antoine Gervais
}

University of Notre Dame

agervais@nd.edu

J. Bradford Jensen

McDonough School of Business

Georgetown University

Washington, DC 20057

and Peterson Institute for International Economics

and also NBER

jbj24@georgetown.edu 


\section{Introduction}

In this paper, we use a unique dataset on the distribution of producers and consumers across regions of the United States to estimate the share of economic activity exposed to international competition, a critical input for evaluating the impact of a broad range of domestic and external shocks. ${ }^{1}$ To date, empirical studies have focused almost exclusively on the exposure of the manufacturing sector, implicitly assuming that services are not tradable. However, because service trade has grown over time and now accounts for about 20 percent of global international transactions (and 30 percent of US exports), the traditional assumption that goods are tradable and services are non-tradable is increasingly inadequate. ${ }^{2}$ Our results suggest that accounting for tradable services nearly doubles the international trade exposure of the American economy.

An important impediment to incorporating service trade into economic models is the lack of information on the scope and characteristics of tradable service industries. Data on international trade in services is far less detailed and comprehensive than that for merchandise trade, so current empirical studies are limited to using bilateral trade data for only a small number of broad service categories (e.g., Anderson et al. (2014); Egger et al. (2012);

1. A number of recent studies depend on estimates of the size of the tradable sector. For example, quantifying the labor market impact of offshoring (Liu and Trefler (2008) and Crino (2010)), the effect of local demand shocks on the labor market (Moretti (2010)), the "jobs multiplier" of fiscal stimulus spending (Wilson (2012)), and the link between real exchange rates and sectoral total factor productivity measures (Berka et al. (2014)). As described in Young (2014), assessing the impact of structural transformation on aggregate productivity will require similar estimates.

2. See Francois and Hoekman (2010) for a review of the growing literature on trade in services. 
Francois and Hoekman (2010)). ${ }^{3}$ Instead, we use a novel dataset derived from the 2007 Economic Census to present a more comprehensive and detailed picture of service trade. Our empirical analysis demonstrates aggregated data mask important variation within service categories and may provide inaccurate measures of the exposure of regions to international trade.

Our dataset collects region-level information on output, demand, and production costs for about one thousand manufacturing and service industries. However, it does not contain information on trade flows between regions. This prevents the implementation of standard estimation procedures, so-called gravity equations, which relate the volume of trade between regions to their economic size and the trade resistance between them. Instead, we develop a method that estimates the effect of trade costs from region-level information on industry output and demand. Our theoretical framework, which is a natural extension of the Anderson and Van Wincoop (2003) gravity model, formalizes the intuition of Jensen and Kletzer (2006) and Jensen (2011) that the disparity between local supply and local demand is an indicator of the extent of trade in an industry. In our model, as trade costs increase, consumers spend an increasing fraction of their income on output produced by local firms, such that regional demand and supply converge. Our estimation method relies on this insight and uses the structure of the theoretical model to infer measures of trade costs from the observed distribution of industry output and demand.

3. As described in Feenstra et al. (2010), the US Census Bureau publishes information on US imports and exports of goods for more than 10,000 product categories, whereas the Bureau of Economic Analysis publishes US services trade data for about 30 categories (up from 17 categories in 2005). 
For the estimation, we focus on trade costs associated with distance between producers and consumers. Services can be delivered at a distance through a variety of modes: shipping (e.g., software publishing); movement of producers (e.g., consultants); or movement of consumers (e.g., amusement parks). ${ }^{4}$ However, independent of the mode of delivery, service trade implies movement across space such that, as in manufacturing, distance between producers and consumers matters. In addition to trade costs, our theoretical framework features other factors that influence the extent of trade between regions, such as differences in production costs across regions, and differences in product differentiation and returns to scale across industries. Because we control for these differences in our estimation and because our estimates are derived from US data (where interregional policy barriers to trade tend to be low), our empirical measures of trade costs represent fundamental product or service characteristics associated with the cost of distance and, as a result, provide useful information on the potential scope for international trade in services. ${ }^{5}$

In our theoretical model, trade flows between regions depend on the "phiness" of trade; a function of the trade costs and price elasticity of demand parameters (e.g., Baldwin et al. (2003)). Conditional on trade costs, trade will be lower in high elasticity industries because demand is more sensitive to changes in price. Disentangling trade costs from elasticity of demand is

4. These methods of delivery are equivalent to the "modes" of service trade defined in the General Agreement on Trade in Services (GATS). In this paper, we define trade as modes 1,2 , and 4 (shipping, and movement of consumers or producers, respectively) and think of mode 3 (local presence) as analogous to foreign direct investment.

5. Similar to goods trade, culture, language, and other measures of "distance" are likely to affect international trade in services. Because we use US data in our estimation, the influence of these factors in our estimates is reduced. 
therefore crucial to obtain accurate measures of the impact of distance on trade flows. An important measurement challenge we face is that measures of price elasticity are not readily available for service industries. Using the theoretical model as a guide, we construct measures of elasticity from data on profit margins collected by the Bureau of Economic Analysis. Our estimates take reasonable values. The average elasticity across all industries in our sample is 7.1. For manufacturing industries, the average is 8.1; a value in line with available estimates (e.g., Broda and Weinstein (2006)).

Our estimation method generates plausible values for trade costs. Consistent with the theoretical model, estimated trade costs are lower in industries characterized by large disparities in supply and demand within regions. We further validate our estimates by comparing them to other indices of tradability that have been used in the literature. As expected, our trade costs measures are negatively correlated with industry-level estimates of trade share and average distance shipped derived from the US Census Commodity Flow Survey (e.g., Head and Mayer (2010); and Holmes and Stevens (2012)). In contrast to our estimates, these measures are outcome variables that reflect variation in multiple fundamentals, only one of which is the impact of distance on trade costs. Our estimates are also negatively correlated with an indicator that captures the extent to which the average task in an industry can be offshored (e.g., Amiti and Wei (2005); Crino (2010); Grossman and Rossi-Hansberg (2008); and Jensen and Kletzer (2010)).

Our empirical results challenge the conventional treatment of services as non-tradable. Our analysis confirms trade costs are higher on average in the 
service sector, but also reveals that many service industries have estimated trade costs comparable to manufacturing industries where we observe trade. We use our measures of trade costs to classify industries into tradable and non-tradable categories. As expected, a smaller share of service industries are tradable. However, because the service sector is relatively large (accounting for about 65 percent of value added in the United States, compared to about 20 percent for manufacturing), we find that about half of the value added in tradable industries comes from the service sector.

Our analysis highlights systematic variation in industry characteristics across tradable and non-tradable industries. On average, tradable industries have higher wages and labor productivity compared to non-tradable industries. These differences persist even when comparing industries within the same sector. We interpret these patterns as evidence of differences in factor-intensity across industries. Assuming wages and labor productivity reflect unmeasured differences in workers' ability and physical or intangible assets, respectively, our results suggest tradable industries are skill- and capital-intensive compared to non-tradable ones. These results are a first step to understanding how the location of services production might respond to changes in international economic policy for services.

The rest of the paper proceeds as follows. In the next section, we motivate the intuition for our empirical strategy by documenting geographical patterns of production for several industries. In section 3, we develop a theoretical model of trade between regions to obtain an analytical expression that relates trade costs to the share of excess supply, a measure of disparity between local production 
and demand. In section 4, we present descriptive statistics on the share of excess supply. In section 5, we discuss the empirical implementation of our model and obtain estimated trade costs for 969 service and manufacturing industries. In section 6 , we use our estimates to characterize the international trade exposure of the US, examine the regional distribution of tradable services, compare the characteristics of tradable and non-tradable industries, and explore the potential welfare gains from trade liberalization in services. Section 7 concludes.

\section{Geographic Concentration}

To motivate our empirical approach, we present examples that illustrate the variation across industries in the geographic concentration of production. Figure 1 depicts the distribution of employment across US counties for two manufacturing industries, "Aircraft" and "Ready-mix concrete," and two service industries, "Software publishing" and "Tax preparation." The underlying data comes from the 2007 County Business Patterns (CBP) program. ${ }^{6}$ Counties in white report zero employment in the industry, while counties in grey report positive employment. ${ }^{7}$

Figure 1 shows there are important differences across industries in the geographic distribution of employment across regions, even within sector. As

6. CBP is publicly available data, so we can provide a more detailed view of the distribution of employment. Census would not allow disclosure of microdata statistics at the county by industry level. See http://www.census.gov/econ/cbp/ for more information on the CBP program.

7. There are over 3,000 counties in the US, so the geographic area of individual counties tends to be small (particularly in the eastern US). We represent county borders in white to help distinguish between producing and non-producing regions; state borders are outlined in black. 
seen in panel (a), aircraft production is concentrated in small number of counties; the four counties that contain Seattle, WA, Fort Worth, TX, and Wichita, KS account for almost half of aircraft manufacturing employment in the US. ${ }^{8}$ In contrast to the geographic concentration of aircraft production, panel (c) shows employment in the Ready-mix concrete industry is distributed throughout the US. The right hand side of Figure 1 reveals similar patterns in the spatial distribution of production in the service sector. As seen in panel (b), employment in the software publishing industry is concentrated in a small number of counties. Together, the 3 counties that contain Seattle, WA and the Silicon Valley region account for almost a quarter of software employment in the US. In contrast, panel (d) shows that employment in the tax preparation industry, which includes firms like H \& R Block, is ubiquitously distributed throughout the US.

Relative to aircraft, ready-mix concrete is characterized by higher transportcost-to-value ratios, while tax preparation is more intensive in face-to-face meetings with clients than software publishing. These differences suggest firms in the concrete and tax preparation industries face higher trade costs compared to firms in the aircraft and software industries. When trade costs are high, interregional sales are low and local production more closely matches local demand. The impact of differences in trade costs across industries is apparent in Figure 1. Consistent with high trade costs, concrete production and tax preparation services are widespread. Conversely, the spatial concentration of

8. In CBP data, some counties' employment is suppressed for disclosure avoidance reasons. In these cases, an employment size class is assigned to the county. For the employment share information reported in this section, we take the mid-point of the size class as the county's employment. 
employment in the aircraft and software industries is far greater than local demand would support, which suggests trade costs are low in those industries. In the next section, we formalize this intuition by developing a model of interregional trade that relates differences in trade costs across industries to differences in the geographic concentration of industry output unexplained by the concentration of demand and other factors.

\section{Theoretical Framework}

In this section, we extend the Anderson and Van Wincoop (2003) model of trade to include multiple industries and increasing returns in production. In our theoretical framework, products are distinguished by their kind and by their place of production, such that regions can produce a differentiated variety in each of the $s=1,2, \ldots, S$ industries. We assume production entails both fixed and marginal production costs. The cost function allows us to define (unobservable) prices as a function of (observable) region characteristics. We use our extension of the gravity model to derive an analytical expression that relates region-level production costs and bilateral trade costs to the industry's share of excess supply, an index of the disparity between the distributions of output and demand across regions. In the following sections of the paper, we use this result to develop a novel estimation strategy that identifies trade costs in the absence of trade data. ${ }^{9}$

9. In contrast, a series of recent papers use the standard gravity model and bilateral trade data to estimate trade costs for service sectors (e.g., Anderson et al. (2014); Egger et al. (2012); van der Marel and Shepherd (2013); and Gervais (2014)). These studies face the limitation that only highly aggregated bilateral trade data is available. 


\subsection{Demand}

We begin by characterizing the behavior of consumers. The economy consists of $J$ regions each inhabited by a mass of identical consumers. Preferences of the representative consumer in any region $i \in J$ are defined over the consumption of differentiated varieties of goods and services in each industry

$$
U_{i}=\prod_{s=1}^{S} Q_{i s}^{\alpha_{s}}, \text { with } Q_{i s}=\left(\sum_{j=1}^{J} \frac{\sigma_{s}-1}{q_{i j s}}\right)^{\frac{\sigma_{s}}{\sigma_{s}-1}}, \sum_{s=1}^{S} \alpha_{s}=1, \text { and } \alpha_{s}>0
$$

where $q_{i j s}$ is the quantity of region- $j$, industry- $s$ variety consumed in region $i$, and $\sigma_{s}>1$ is the price elasticity of demand in industry $s$.

The representative consumer maximizes her utility subject to her budget constraint. The consumer's problem can be solved in two steps. First, because the outer tier of preferences are Cobb-Douglas, the optimal expenditure on each industry is given by $E_{i s}=\alpha_{s} E_{i}$, where $E_{i}$ is region $i$ 's total expenditure. Second, within each industry $s$, the consumption of varieties is chosen to minimize the cost of the aggregate bundle $Q_{i s}$. Region $i$ 's optimal expenditure on an industry $s$ variety produced in region $j$ is

$$
r_{i j s}=E_{i s}\left(\frac{p_{i j s}}{P_{i s}}\right)^{1-\sigma_{s}}, \quad \text { with } \quad P_{i s}=\left(\sum_{j=1}^{J} p_{i j s}^{1-\sigma_{s}}\right)^{\frac{1}{1-\sigma_{s}}}
$$

where $p_{i j s}$ is the price of a unit of differentiated output and $P_{i s}$ is the price of a unit of the aggregate bundle $Q_{i s}$, so that $E_{i s}=P_{i s} Q_{i s}$. 


\subsection{Supply}

We now characterize the supply side of the economy. Production entails both fixed and marginal production costs and requires only one input, labor. The total cost function for each region-industry is given by

$$
C_{j s}=w_{j}\left(F_{s}+\frac{1}{z_{j s}} \sum_{i} \tau_{i j s} q_{i j s}\right) .
$$

Production costs vary across regions and industries because of changes in wage rates and labor requirements. The wage rate $w_{j}$ is region-specific, reflecting differences across regions in labor costs, whereas labor efficiency $z_{j s}$ is regionindustry specific, reflecting productivity differences across industries within regions. Output can be traded across regions at some cost. As is customary, we assume these costs take the iceberg form such that when $\tau_{i j s} \geq 1$ units of product $s$ is shipped from region $j$ to region $i$, only one unit arrives. There are no intra-regional trade costs, i.e., $\tau_{j j s}=1 \forall j, s$. The presence of fixed production costs, $F_{s}$, implies that each region will produce a unique variety.

We assume there is monopolistic competition in final output markets and that regions are segmented markets. In that case, profit maximization implies the following pricing rule

$$
p_{i j s}=\left(\frac{\sigma_{s}}{\sigma_{s}-1}\right) \frac{w_{j} \tau_{i j s}}{z_{j s}} .
$$

Equation (4) makes clear that prices are increasing in wages and bilateral trade costs, and decreasing in technical efficiency. The constant elasticity of 
substitution across varieties implies a constant markup, $\sigma_{s} /\left(\sigma_{s}-1\right)$, above marginal costs. This markup depends only on the price elasticity of demand and varies across industries, but not across regions within-industries. When industry output is highly differentiated, the price elasticity of demand is low and markups are high. The variation across industries in profit margins will play a key role in our measurement strategy. Because of fixed production costs, average price may be lower than average cost if the region does not sell enough units. ${ }^{10}$ Profit maximizing regions produce if and only if it makes positive profits in that industry, such that our model is consistent with non-producing regions.

\subsection{Interregional Trade}

We now combine the supply- and demand-side of the economy to characterize trade flows between regions. Substituting the pricing rule (4) into the optimal expenditure (2), we can express interregional sales from region $j$ to $i$ in industry $s$ as

$$
r_{i j s}=\left[\frac{\left(w_{j} \tau_{i j s} / z_{j s}\right)^{1-\sigma_{s}}}{\sum_{l \in J_{S}}\left(w_{l} \tau_{i l s} / z_{l s}\right)^{1-\sigma_{s}}}\right] E_{i s}, \quad \forall j \in J_{s},
$$

where $J_{s}$ denotes the set of regions producing output in industry $s$. Equation (5) is a typical gravity equation. It shows that interregional sales are increasing in destination-region total expenditure $\left(E_{i s}\right)$ and decreasing in producer-region production costs $\left(w_{j} / z_{j s}\right)$, and the trade costs between regions $\left(\tau_{i j s}\right)$. The term

10. From equations (3) and (4), the minimum quantity such that regions make positive profits is given by $q_{j s}^{\text {min }} \equiv \sum_{i} \tau_{i j s} q_{i j s}=\left(\sigma_{s}-1\right) F_{s} z_{j s}$. 
in square brackets shows that region expenditures is allocated across varieties according to their contributions to the price index.

In our data, we do not have information on interregional sales, $r_{i j s}$. Therefore, we cannot use gravity equation (5) to estimate trade costs, $\tau_{i j s}$. Instead, we derive information on the extent of interregional trade from the excess supply (ES), defined as the region-industry level difference between local supply and local demand. The ES is, in essence, a region-industry level measure of current account. For example, when supply in a region-industry is greater than demand, the ES is positive and the region is a net exporter. In the model, revenue in each region-industry is obtained by taking the sum across all destinations of interregional sales, defined in (5). Because there are no fixed trade costs, regions will sell their output in all regions such that

$$
E S_{j s} \equiv R_{j s}-E_{j s}= \begin{cases}\sum_{i} \frac{\left(w_{j} \tau_{i j s} / z_{j s}\right)^{1-\sigma_{s}} E_{i s}}{\sum_{l \in J_{S}}\left(w_{l} \tau_{i l s} / z_{l s}\right)^{1-\sigma_{s}}}-E_{j s}, & \text { if } j \in J_{s}, \\ -E_{j s}, & \text { otherwise. }\end{cases}
$$

Equation (6) shows that, all else equal, low-cost regions that face low barriers to trade will generate greater revenue and have larger excess supply. It also makes clear the variation we exploit to identify the trade cost parameters. On the one hand, when trade costs are null (i.e., $\tau_{i j s}=1$ ), firms face the same aggregate demand independent of their location such that production is distributed across regions in proportion to production costs only (i.e., $E S_{j s} \neq 0$ ). On the other hand, production will equal consumption in each region when trade costs are prohibitive (i.e., $E S_{j s}=0$ ). 
Equation (6) makes clear that because the ES is a function of the region-level expenditures, it is positively correlated with industry size. To obtain measures that are comparable across industries, we define the share of excess supply (SES) for each industry $s$ as follows

$$
S E S_{s}=\frac{\sum_{j}\left|E S_{j s}\right|}{2 R_{s}}
$$

where $R_{s}=\sum_{j} R_{j s}$ denotes total revenue in the industry. We use the absolute value because, by construction, the sum across regions of $E_{j s}$ is equal to zero. The $S E S_{s}$ ranges between 0 and 1. A high $S E S_{s}$ signals that some regions produce a significantly higher share of the industry's output, and others significantly lower, than is consumed in the region. For example, when $S E S_{s}=0$ production equals consumption in all regions, and when $S E S_{s}=1$ production is located in a subset of regions disjoint from the set of regions where consumption takes place. Because there is intra-industry trade in our model, the $S E S_{s}$ provides a lower bound estimate for the share of interregional sales in the industry.

Together, equations (6) and (7) provide a theoretical expression for the SES and play a central role in the empirical analysis below. Equation (6) shows that the SES depends on the distributions of supply, demand, production costs, and trade costs across regions. ${ }^{11}$ As explained in detail in the following sections, it is possible to use information on revenue, expenditure, wages, and labor

11. Fixed production costs do not appear directly in those equations, but the effect of changes in fixed production costs are captured indirectly through variation in the number of regions that produce output (i.e., differences in $J_{s}$ across industries). All else equal, high fixed costs industries will be characterized by a smaller number of producing regions. 
productivity to infer measures of trade costs from these equations, i.e., without bilateral trade data. We note that while our model accounts for a large number of factors that affect the extent of trade between regions, it remains tractable and provides a flexible framework to evaluate the impact of trade costs on interregional trade.

\section{Share of Excess Supply}

In this section, we provide information on the $S E S_{s}$ defined in equation (7); the key statistics of the data we use to estimate industry-level measures of trade costs. We begin with a discussion of the dataset we use for our empirical analysis. We then explain how we measure the two components of the SES, region-industry revenue and expenditure. Finally, we present descriptive statistics for $S E S_{s}$, defined in (7).

For the empirical analysis, we use data from the US Census Bureau's 2007 Economic Census. The Economic Census collects information on revenue, payroll, employment, location and principal industry for almost all establishments located in the US. We use this information to construct a region-industry level dataset. We define an industry as a six-digit North American Industrial Classification System (NAICS) category, the most disaggregated level available. We partition the US into regions using the Bureau of Economic Analysis' Eco-

nomic Areas (EA) as our unit of geography. As described in Johnson and Kort (2004), EA group together cities and adjacent counties based on commuting patterns and other indicators of interaction. In contrast with other available 
measures of geography, such as state, county, or zip code, EAs are consistent with the notion of a "geographic market." The 183 EAs are mutually exclusive and exhaustive of the land area of the United States. The Data Appendix at the end of the paper provides more details on the Economic Census and the construction of our sample.

Following our model, we measure region-industry revenue, $R_{j s}$, using information on total sales in industry $s$ reported by producers located in region j. As described in the Data Appendix at the end of the paper, we adjust our measures of revenue to account for international transactions. To construct region-industry expenditure, $E_{i s}$, we use information from the Bureau of Economic Analysis' 2007 Input-Output Use table to identify how demand for industry s's output is distributed across consuming industries, investment, government, and final demand. We combine the input-output information with data on the location of demand from the Economic Census and the American Community Survey (for final demand and industries not in scope for the Economic Census). As explained in the Data Appendix, we adjust the demand measures to account for imports using information from Bureau of Economic Analysis' supplemental import matrix.

Using our industry-region measures of expenditure and revenue, we compute $S E S_{s}$ as defined in equation (7) for each of the 969 service and manufacturing industries in our sample. Table 1 lists the most and least concentrated manufacturing and service industries as measured by $S E S_{s}$. Recall that a high SES indicates that production is concentrated in some regions beyond what can be explained by the concentration of demand in those regions. The results 
reported in Table 1 show there is considerable variation in the measured $S E S_{s}$ across industries. The highest $S E S_{s}$ measure is 0.94 for Sheer Hosiery Mills and the lowest $S E S_{s}$ measure is 0.06 for Offices of Dentists.

\section{[ TABLE 1: HERE ]}

As reported in Table 1, there is substantial variation in measured $S E S_{s}$ within the manufacturing sector. Manufacturing industries characterized by high transport-cost-to-value ratios, such as ready-mix concrete and quick printing, have low estimated $S E S_{s}$ measures. Conversely, manufacturing industries with lower transport-cost-to-value ratios such as Tobacco, Sugar, and Batteries all have high $S E S_{s}$ measures. Consistent with the model, these results suggest the $S E S_{s}$ reflects variation in trade costs across industries. Table 1 also show considerable variation in estimated $S E S_{s}$ across service industries. Geophysical Surveying and Mapping Services, Electronic Auctions, and Credit Card Issuing, all have $S E S_{s}$ measures of about 0.80, while Office Supply Stores, Supermarkets, Restaurants and Dentists all have $S E S_{s}$ measures below 0.10. While measures of $S E S_{s}$ for service industries are not quite as high as in manufacturing, there is still a considerable amount of services consumed outside the region where they are produced. For instance, by definition of the $S E S_{s}$, (at least) 80 percent of revenue in the electronic auction industry is generated from interregional sales.

To provide a more comprehensive description of the $S E S_{s}$ measures, we presents the mean and standard deviation across all industries and by broad industry groups in Table 2. The simple average of $S E S_{s}$ across all industries implies that (at least) 45 percent of revenue in the average industry is associated 
with transactions in which the buyer and the seller are located in different geographical regions. The standard deviation across industries is large at 0.21 and indicates substantial variation in measured $S E S_{s}$. The results also show that manufacturing industries are the most concentrated on average, with an $S E S_{s}$ of 0.59 , retail industries are the least concentrated, with an $S E S_{s}$ of 0.21 . Within services, the broad industry groups Transportation, Information, and Finance and Insurance group all have relatively high average $S E S_{s}$ of about 0.45 .

\section{[ TABLE 2: HERE ]}

The results reported in Table 2 reveal considerable variation in estimated $S E S_{s}$ across industries within broad groups. For instance, the mean and standard deviation across Information industries are 0.45 and 0.17 , respectively. By comparison, the mean and standard deviation across all industries in the sample are 0.45 and 0.21 , respectively. This implies there is as much variation across industries within the Information group as across all industries in the sample. Therefore, classifying all industries within a broad group as either tradable or non-tradable is equivalent to assuming that all industries in our sample are either tradable or non-tradable.

\section{Estimating Trade Costs}

In this section, we use our theoretical model and data to obtain industry-level estimates of trade costs from our measures of $S E S_{s}$. We first describe the empirical implementation of the model. We then discuss measurement issues 
we face and how we address them. Finally, we present the estimation results and compare our estimates with alternative measures of tradability that have been used in the literature. In section 6 , we use our estimates of trade costs to evaluate the scope for trade in services.

\section{$5.1 \quad$ Empirical Approach}

Taking the sum across regions of interregional sales defined in equation (5), we can express region-industry revenue as

$$
R_{j s}=\sum_{i=1}^{J} \frac{\lambda_{j s} \phi_{i j s} E_{i s}}{\sum_{l \in J_{s}} \lambda_{l s} \phi_{i l s}} \quad \text { with } \quad \lambda_{j s}=\left(\frac{w_{j}}{z_{j s}}\right)^{1-\sigma_{s}}, \text { and } \phi_{i j s}=\tau_{i j s}^{1-\sigma_{s}}
$$

This equation shows that region-industry revenue depends (only) on the distributions of industry expenditure across regions, and two sets of parameters. The first parameter, $\lambda_{j s}$, is a function of production costs. The second parameter, $\phi_{i j s}$, is known as the "phi-ness" of trade and captures the impact of trade costs on revenue (e.g. Baldwin et al. (2003)). Substituting (8) into the share of excess supply (7) yields

$$
S E S\left(\boldsymbol{\lambda}_{s}, \phi_{s}, \boldsymbol{E}_{s}, R_{s}\right)=\frac{\sum_{j}\left|R_{j s}\left(\boldsymbol{\lambda}_{s}, \boldsymbol{\phi}_{s}, \boldsymbol{E}_{s}\right)-E_{j s}\right|}{2 R_{s}}
$$

where $\boldsymbol{\lambda}_{s}, \phi_{s}$, and $\boldsymbol{E}_{s}$ denote $J \times 1$ vectors. Using our data, we can construct measures of revenue, expenditure, and obtain controls for the vector of $\lambda_{j s}$. Therefore, for any given vector of trade costs, $\boldsymbol{\phi}_{s}$, we can use equation (9) to obtain a "simulated" SES. 
In our data, we have only 183 observations for each industry (one per region). Therefore, we cannot identify the bilateral trade cost parameters, $\phi_{i j s}$, without making additional assumptions. Trade in services implies movement across space of either the output, the consumer, or the producer so that, as in manufacturing, distance between producers and consumers is an important determinant of trade costs. Therefore, we follow the gravity equation literature and assume bilateral trade costs are proportional to distance between regions. ${ }^{12}$ We assume that trade costs are related to distance as follows

$$
\phi_{i j s}= \begin{cases}\left(1+t_{s} d_{i j}\right)^{1-\sigma_{s}} & \text { if } i \neq j \\ 1, & \text { otherwise }\end{cases}
$$

where $d_{i j}$ is a measure of distance between the largest counties of each EA. Using the $J \times J$ matrix of bilateral distance $\boldsymbol{D}$ and information on measures of elasticity, we can construct the vector $\boldsymbol{\phi}_{s}\left(t_{s}, \sigma_{s}, \boldsymbol{D}\right)$ using equation (10) for any given value of the trade cost parameter $t_{s}$.

Combining (9) and (10) implies the $S E S_{s}$ depends on data and one parameter, $t_{s}$. Our estimation strategy is to calibrate our model by choosing the value of $t_{s}$ which minimizes the difference between the simulated and the measured SES. In other words, we define

$$
\widehat{t}_{s} \equiv \underset{t_{s}}{\operatorname{argmin}} \mu\left(t_{s}\right)=\left(S E S\left(t_{s} \mid \boldsymbol{\lambda}_{s}, \sigma_{s}, \boldsymbol{D}, \boldsymbol{E}_{s}, R_{s}\right)-S E S_{s}\right)^{2},
$$

12. Because policy restrictions to trade between regions within the US are relatively small compared to international trade, we ignore border effects and focus on distance as the main impediment to trade. 
where $S E S_{s}$ denotes the share of excess supply measured from the data. In the estimation, we take the distribution of demand and expenditure across regions as exogenous and simply ask which value of the trade cost parameter is consistent with these observed distributions.

\subsection{Measurement}

Before we present the estimation results, we discuss two additional measurement issues we face. Estimating equation (11) requires data on revenue, expenditure, and production costs for each region-industry, as well as information on the elasticity of substitution for each industry. We use the same measures of

revenue, $R$, and expenditure, $E$, as in section 3 above, so we only discuss the construction of the elasticity of demand, $\sigma_{s}$, and the production cost parameters, $\lambda_{j s}$. Additional details on the construction of these variables are provided in the Data Appendix.

\subsubsection{Elasticity of Demand}

Industry-level measures of the elasticity of demand are not readily available for the service sector, so we need to construct our own. We use a relationship identified in the theoretical model to construct $\sigma_{s}$ for each industry. From the pricing rule (2) and the optimal demand (4), it follows that

$$
\widehat{\sigma}_{s}=\frac{R_{s}}{G_{s}},
$$


where $G_{s} \equiv\left(1 / \sigma_{s}\right) \sum_{i} \sum_{j \in J_{s}}\left(r_{i j s}-F_{s}\right)$ denotes gross operating surplus in the industry. Equation (12) shows that the price elasticity of demand is equal to the inverse of an industry-level measure of gross profit margins.

We estimate the elasticity of demand using equation (12) and information on value added and gross operating surplus from the Bureau of Economic Analysis' Gross-Domestic-Product-by-Industry data. Our estimates take reasonable values. The average elasticity for manufacturing industries is 8.1. Using trade data, Broda and Weinstein (2006) obtain averages across manufacturing industries of 4.0 or 17.3 depending on the period and level of aggregation. An advantage of our approach and data set is that we can obtain estimates for the elasticity of demand using the same methodology and data for manufacturing and service industries. The average elasticity for services is 6.2 . The lower elasticity indicates services are less differentiated on average compared to manufacturing goods.

\subsubsection{Production Costs}

To construct the region-industry measures of production costs, $\lambda_{j s}$, we need information on wages and technical efficiency. We measure the wage rate by dividing total payroll by total employment in each region. The data does not contain information on physical output and, for many industries, the only input on which we have information is labor. As a result, we cannot compute measures of technical efficiency such as physical total factor productivity or quantity produced per worker, or even value added per worker. Therefore, we measure region-industry's technical efficiency using labor productivity defined 
as sales per worker. Our estimate of $\lambda_{j s}$ is defined as follows

$$
\widehat{\lambda}_{j s}=\frac{\text { Sales }_{j s} / \text { Workers }_{j s}}{\text { Payroll }_{j} / \text { Workers }_{j}}
$$

The Data Appendix at the end of the paper provides more information on the construction of this measure.

As shown in the Data Appendix, the ratio of output per worker to wages for region $j$ industry $s$ in our theoretical model is given by

$$
\widehat{\lambda}_{j s} \equiv \frac{r_{j s} / l_{j s}}{w_{j}}=\left(\frac{\sigma_{s}}{\sigma_{s}-1}\right)\left[1-\frac{1}{1+\left(\frac{\sigma_{s}-1}{\sigma_{s}}\right)^{\sigma_{s}}\left(\frac{w_{j} A_{j s}}{F_{s}}\right) \lambda_{j s}}\right]
$$

where $A_{j s}=\sum_{i} E_{i s} P_{i s}^{\sigma_{s}-1} \tau_{i n s}^{1-\sigma_{s}}$ is the region-industry market access term. This expression makes clear that our proxy is positively correlated to the model parameter $\lambda_{j s}$. As in Foster et al. (2008), equation (14) shows that our revenuebased cost measure $\widehat{\lambda}_{j s}$ is positively correlated with region-industry technical efficiency, but also reflects differences in demand $\left(A_{j s}\right)$. In addition, in our model differences in fixed production costs and elasticity of demand across industries lead to variation in estimated production costs. Because we implement our estimation procedure separately for each industry, these differences will not drive any of the results. 


\subsection{Results}

In this section, we present the calibration results for our model. For each industry, we find the value for the trade cost parameter $t_{s}$ consistent with our measure $S E S_{s}$. Because the relationship between the excess supply and trade costs is non-linear, we use numerical methods to search over values of $t_{s}>0$. For each guess $\tilde{t}_{s}$, we use our data on expenditure $\left(\boldsymbol{E}_{\boldsymbol{s}}\right)$ and distance $(\boldsymbol{D})$, and our measures of price elasticity of demand $(\widehat{\sigma})$ and production costs $\left(\widehat{\lambda}_{j s}\right)$ to construct the simulated $S E S\left(\tilde{t}_{s}\right)$ defined in (9). As shown in equation (11), we define our estimated trade costs, $\widehat{t}_{s}$, as the parameter that minimizes the distance between the simulated and actual SES.

We report the estimation results in Table 3. Overall, our model performs well. ${ }^{13}$ As indicated in the table, the objective function $\mu\left(\widehat{t}_{s}\right)$, defined as the square of the difference between actual and simulated share of excess supply, is close to zero on average. As seen in the table, the manufacturing sector has the lowest average estimated trade costs while retail trade has the highest. The empirical results also show there is considerable variation within sectors in the estimated trade costs. In all cases, the standard deviation in estimated trade costs across industries within broad industry groups is large relative to the average.

13. For 60 industries, our estimates of trade costs do not conform with our priors. These industries typically have an SES above 0.5 and an estimated trade cost above 5 . Rather than exclude these outliers from the analysis, we impute a value for $\widehat{t}_{s}$ to these industries using the simple empirical relationship between $S E S_{s}, \sigma_{s}$, and $\widehat{t}_{s}$ observed in other industries. Most outliers are in the manufacturing sector ( 54 of 60 ), so our imputation reduces the average trade cost in manufacturing (which works against finding tradable services in our analysis below). Our results are robust to excluding these industries, which together account for only about 1.6 percent of value added. 


\section{[ TABLE 3: HERE ]}

Figure 2 provides a detailed view of the within industry group dispersion in estimated trade costs. Each panel plots our estimates, $\widehat{t}_{s}$, against the share of excess supply for one of twelve groups. Each dot represents a six-digits NAICS industry. Panel (a) shows manufacturing industries have relatively low trade costs compared to services industries represented in the other panels. Comparing across panels reveals the substantial variation in estimated trade costs across industries within each sector and the considerable overlap between the estimated trade costs of manufacturing and service industries. As expected, there is a negative correlation between estimated trade costs and $S E S_{s}$. Across all industries, the correlation is equal to -0.61. Figure 2 makes clear the negative correlation between estimated trade costs and SES is very robust. It holds within each major industry group and is not due to the influence of a few individual industries. ${ }^{14}$

\section{[ FIGURE 2: HERE]}

\subsection{Validation}

To further confirm our trade cost measures capture useful variation in trade costs across industries, we compute correlations between our estimates and several measures that are used as proxies for international trade intensity. Our first measure is an industry-level estimate of trade share derived from

14. We note that we restricted $t_{s} \in[0,25]$ for the estimation. While many industries in the Real estate broad industry group attain that upper bound, this restriction has no impact on the empirical analysis we present below. 
Bureau of Economic Analysis' input-output tables. Our second measure uses information from the Commodity Flow Survey (CFS) to estimate the average distance shipped for each industry (e.g., Head and Mayer (2010); Holmes and Stevens (2012); and Yilmazkuday (2012)). Our third measure is an indicator derived from occupation characteristics that captures the extent to which the average task in an industry can be offshored (e.g., Amiti and Wei (2005); Crino (2010); Grossman and Rossi-Hansberg (2008); and Jensen and Kletzer (2010)). Additional information on these measures is available in the Data Appendix.

We report the correlations between the trade indices and our estimated trade costs in Table 4. In all cases, the correlation is negative as expected; Industries with higher estimated trade costs are observed to have lower trade barriers. At the same time, the magnitude of the estimated correlations imply there are important differences between those measures. Our estimates have several advantages over the other indices. First, the BEA trade share and the CFS average distance shipped measures have similar limitations to using $S E S_{s}$ as a proxy for trade costs. Each is an outcome variable that reflects variation in multiple fundamentals, one of which is the impact of distance on trade costs. Second, because the CFS collects information on output shipments, the vast majority of service industries are out of scope. Therefore, the CFS index cannot be used to construct measures of trade costs for service industries. Third, the occupation-based measure captures the extent to which tasks can be traded or not, not the impact of distance on interregional sales. ${ }^{15}$ For these reasons, we

15. In addition, tradability indices that use occupation characteristics to determine tradability often focus on whether the worker in the occupation needs to be physically present with co-workers to do their job. This results in many production jobs (and as a result many manufacturing industries) being classified as "non-tradable." 
believe our estimated trade costs have advantages over these other measures to address questions related to the exposure of the economy to international shocks.

[ TABLE 4 HERE ]

\section{Tradable Services}

In this section, we explore the empirical implications of our trade cost estimates. First, we compute the share of service production in the US that could be traded internationally and examine the geographic distribution of trade exposure. We then compare average wages and labor productivity in tradable and nontradable industries. Last, we use the model to quantify the potential welfare gains from trade liberalization in the service sector.

\subsection{Value Added}

To identify how much economic activity is in tradable service industries, we classify industries as "tradable" or "non-tradable" based on a threshold trade cost. Because we have priors on the tradability of output in the manufacturing sector, we use our trade cost estimates for manufacturing industries to define this threshold. For each $y \in[0,100]$, we find the threshold trade cost $t_{y}$ that results in $y$ percent of manufacturing sector value added being classified as tradable. We use these thresholds to group services industries into tradable (i.e., $\widehat{t}_{s} \leq t_{y}$ ) and non-tradable categories (i.e., $\widehat{t}_{s}>t_{y}$ ). 
Table 5 presents the distribution of value added across broad industry groups and tradability assuming that 75 percent of manufacturing value added is in tradable industries (i.e., using $t_{75}$ as our threshold). While the average service industry has higher trade costs than the average manufacturing industry, because the service sector is larger than the manufacturing sector, there is significant value added in tradable service industries. We find that about 20 percent of aggregate value added is produced in industries classified as tradable and that the service sector accounts for almost half of tradable value added. These results imply that accounting for services almost doubles the estimated size of the tradable sector in the US and calls into question the common assumption that services are not tradable.

\section{[ TABLE 5 HERE ]}

The results in Table 3 and Table 5 highlight the advantage of using detailed, industry level data to estimate trade costs for the service sector. Currently available international trade data for the service sector is highly aggregated, nearly as aggregated as the 11 service industry categories reported in Table 3. So, any estimate of trade costs derived from international trade data would aggregate a range of industries with different trade costs. If we compare the average trade cost for the sectors reported in Table 3 to the 75 percent threshold, $t_{75}=1.45$, no service sector would be classified as tradable, biasing downward the estimate of the trade exposure of the US economy. These results suggest that highly aggregated data hides important variation in the tradability of service activities. 
The results in Table 5 are based on the hypothesis that 75 percent of manufacturing employment is in tradable industries. To evaluate the sensitivity of this result to changes in the threshold, we compute $t_{y}$ for each $y \in\{5,10, \ldots, 95\}$ and reclassify industries according to each threshold. Figure 3 shows the share of total value added in industries classified as tradable separately for manufacturing and services. By construction, the share of tradable manufacturing sector value added is a 45 degree line. Two important findings emerge from Figure 3. First, the share of value added in tradable industries is evenly distributed across manufacturing and services for tradability thresholds, $t_{y}<0$. 8 . Second, for $t_{y}>0.8$ the value added in tradable services is larger than in manufacturing. Therefore, the finding that accounting for services doubles the estimated size of the tradable sector is robust to our choice of threshold and, for reasonable assumptions regarding the tradability of manufacturing industries, services account for a larger share of tradable industry value-added.

\section{[ FIGURE 3 HERE ]}

\subsection{Geographic Distribution of Trade Exposure}

The results in the previous section suggest that the trade exposure of the US economy is significantly higher due to tradable services. However, because of geographical concentration in production of tradable services (e.g., securities and commodities trading, motion pictures, computer systems design and support industries, or casinos), it may be the case that not all regions are affected equally. In this section, we present information on the geographical distribution 
of tradable service industries to explore how services trade liberalization may impact regions differently.

\section{[ FIGURE 4 HERE ]}

Figure 4 reports the share of value added in tradable service industries for each EAs. As seen in the figure, every EA produces some tradable services, but the relative importance of these industries vary significantly across regions. EAs in black, (e.g., Austin, Las Vegas, New York, San Francisco, and Washington) all have more than 15 percent of region value added in tradable service industries, while EAs in dark grey (e.g., Boston, Chicago, Denver, and Los Angeles) all have more than 10 percent of region value added in tradable service industries. Most of these regions have relatively small manufacturing sectors, so tradable services represent a significant increase in these regions' trade exposure. In contrast, many other EAs have less than 5 percent of region value added in tradable services.

Figure 4 shows that the uneven concentration of production of tradable service industries implies the international trade exposure of regions varies significantly and highlights an advantage of using disaggregated data to estimate trade costs. For example, this distinction could also be important when comparing the trade exposure of different countries.

\subsection{Characteristics of Tradable Industries}

We use our estimated trade costs to compare tradable and non-tradable industry characteristics. In our model, production requires only one input, labor. In 
the data, variation in average wages across industries may reflect changes in the skill composition of the labor force. At the same time, measures of labor productivity will capture variation in unmeasured input across industries (e.g., capital intensity, possibly either physical or knowledge). We compare the characteristics of tradable and non-tradable industries using OLS regressions of the form

$$
\ln Y_{s}=\beta_{0}+\beta_{t} \mathrm{ID}_{75}+\mu_{s}
$$

where $Y_{s}$ denotes, in turn, $\log$ co-worker average wage and log labor productivity and $\mathrm{ID}_{75}$ is an indicator variable equal to 1 if the industry is classified as tradable (i.e. if $\widehat{t}_{s}<t_{75}$ ), and 0 otherwise. We report the results in panel $\mathrm{A}$ of Table 6 . The estimation results shows there are important differences between tradable and non-tradable industries. On average, workers in tradable industries are about 30 percent more productive and receive 30 percent higher wages compared to workers in non-tradable industries.

\section{[ TABLE 6 ]}

The estimated differences between tradable and non-tradable industry characteristics could be driven by the sectoral composition of each group. For instance, we know from previous results that a larger share of manufacturing industries are classified as tradable. To account for this possibility, we replace the constant $\beta_{0}$ in equation (15) with a set broad industry group dummies. We present the results in panel B of Table 6 . The point estimates are smaller but the systematic differences between tradable and non-tradable remain even within broad industry groups. Tradable industries have 16 percent higher labor 
productivity compared to non-tradable industries in the same group, and 24 percent higher average wages. In panel C, we re-estimate the regressions restricting the sample to services industries only. The results show that workers' wages and productivity in tradable services industries are almost 30 percent higher than in non-tradable industries

Overall, the results reported in Table 6 suggest there are significant differences between tradable and non-tradable industries even within the same sector. We interpret the average wage differences as suggestive evidence that tradable industries use more skill-intensive technologies compared to non-tradable industries, and the labor productivity differences as suggestive evidence that tradable industries are more intensive in other inputs like physical capital or intellectual property capital. These results suggest that simplifying assumptions regarding the tradability of sectors or groups of industries based on highly aggregated data hide important variation in tradability, average wages, and labor productivity that may mask differential factor demands.

\subsection{Potential Gains from Trade}

Last, we consider the potential welfare gains from trade liberalization in the service sector. For simplicity, we assume that changes in trade costs have no general equilibrium impact on wages, and focus on the first order impact on 
prices. ${ }^{16}$ From equations (2) and (4), the price index is:

$$
P_{i s}=\left[\sum_{j \in J_{s}}\left(\frac{w_{j} \tau_{i j s}}{z_{i j s}}\right)^{1-\sigma_{s}}\right]^{\frac{1}{1-\sigma_{s}}}
$$

Therefore, a symmetric change in trade costs of the form $\tau_{i j s}^{1}=\delta \tau_{i j s}^{0}$ for some $\delta>0$, leads to an equivalent change in the price index, $P_{i s}^{1}=\delta P_{i s}^{0}$. From equation (1), log welfare is defined as the weighted sum of the log price indices, where the weights are given by the share of expenditure in each industry. Then, if $\Omega_{y}$ represents the set of industries that are tradable (i.e. $t_{s}<t_{y}$ ), a symmetric change in trade costs leads to the following change in welfare

$$
\% \Delta W=\ln \delta \cdot \sum_{s \in \Omega_{y}} \alpha_{s}
$$

The model shows that the gains from trade are equal to the product of the percentage change in trade costs and the share of demand affected by the change in trade costs.

Table 7 presents the distribution of welfare gains associated with a symmetric liberalization assuming the threshold for tradability is $\tau_{75}$. As expected, given the share of value added in tradable service industries, the potential welfare gains in the service sector are of a similar magnitude to welfare gains in the manufacturing sector. This simple exercise shows that, for similar reductions in trade barriers, gains from liberalization in services trade are of the same

16. This would be the case if we included a homogenous good produced under constant returns to scale and traded at no cost in our model. Changes in wages across regions would then reflect variation in worker productivity in the homogenous good industry and variation in trade costs in the differentiated sector would have no impact on equilibrium wages. 
order of magnitude as the gains in manufacturing. However, existing evidence suggests that policy restrictions in the service sector are significantly higher than in manufacturing. (e.g. Hufbauer et al. (2010)). Therefore, welfare gains from trade liberalization in the service sector could potentially be much larger than those in manufacturing.

\section{[ TABLE 7 HERE ]}

\section{Conclusion}

Because of data limitations, current empirical studies of international trade in services are limited to a small number of relatively aggregated service categories. In this paper, we develop an estimation methodology that exploits information on the spatial distribution of producers and consumers across US regions to obtain measures of trade costs for almost one thousand manufacturing and service industries. Overall, our empirical results suggest that aggregating industries into broad sectors and characterizing these sectors as either tradable or non-tradable hides important differences across industries within sectors in trade costs and industry characteristics.

Estimated trade costs are higher on average in the service sector than in manufacturing, but many service industries have estimated trade costs comparable to manufacturing industries. Using our measures, we classify industries into tradable and non-tradable categories and find that accounting for tradable services almost doubles the international trade exposure of the US economy. This suggests that potential welfare gains from trade liberalization in the ser- 
vice sector are large. We also find that tradable industries have higher average wages and labor productivity, differences that persist even when we compare industries within the same sector. We interpret these differences as evidence of differential factor demands in tradable and non-tradable industries.

Our results have caveats. First, we abstract from non-homotheticity. It is well-known that services share of expenditure is increasing in income per capita. While variation across regions of the US may not be as large as across countries, and final demand is only a fraction of total demand in each industry, it is possible that non-homotheticity plays a role in explaining production patterns. Second, our model does not include firm heterogeneity and selection into exporting, both of which feature prominently in recent trade literature (e.g., Melitz (2003) and Bernard et al. (2003)). ${ }^{17}$ Third, our theoretical framework ignores the location decision of firms, which prevents us from doing counterfactual analysis. These are important topics for future research.

However, because our approach is easy to implement and requires only information on the geographic distribution of production, it is potentially widely applicable. For instance, Europe, where data is increasingly collected on a consistent basis across national borders, could provide a rich empirical context to apply this framework. Comparing our estimates, derived from US data where interregional barriers to trade are relatively low, with estimates from European data could provide useful insight into trade barriers to services

17. There is a growing literature using firm-level micro data to analyze service firms that trade with findings similar to studies of manufacturing firms (e.g. Bernard and Jensen (1999)). See for example Jensen (2011) for the US, Breinlich and Criscuolo (2011) for the UK, Ariu et al. (2012) for Belgium, Guillaume et al. (2011) for the EU, and Kelle et al. (2013) for Germany. 
within Europe. Our procedure is flexible and could be used to estimate the impact of national borders and policy impediments on trade in services in other contexts as well. More generally, distinguishing between tradable and non-tradable activities at a detailed industry level is likely to improve empirical estimates of the impact of a broad range of economic shocks, from the gains to trade liberalization to the labor market effects of offshoring to accurately appraising the empirical impact of fiscal policy or other domestic shocks. 


\section{References}

Amiti, M. and S.-J. Wei (2005). Fear of service outsourcing: is it justified? Economic policy 20(42), 308-347.

Anderson, J. E., C. Milot, and Y. Yotov (2014). How much does geography deflect services trade? International Economic Review (forthcoming).

Anderson, J. E. and E. Van Wincoop (2003). Gravity with gravitas: A solution to the border puzzle. American Economic Review 93(1), 170-192.

Ariu, A. et al. (2012). Services versus goods trade: Are they the same? Centre for Economic Policy Research.

Baldwin, R., R. Forslid, P. Martin, G. Ottaviano, and F. Robert-Nicoud (2003). The core-periphery model: Key features and effects. The Monopolistic Competition Revolution in Retrospect, 213-235.

Berka, M., M. B. Devereux, and C. Engel (2014). Real exchange rates and sectoral productivity in the eurozone. National Bureau of Economic Research.

Bernard, A. B., J. Eaton, J. B. Jensen, and S. Kortum (2003). Plants and productivity in international trade. American Economic Review 93(4), $1268-1290$.

Bernard, A. B. and B. J. Jensen (1999). Exceptional exporter performance: cause, effect, or both? Journal of international economics 47(1), 1-25. 
Breinlich, H. and C. Criscuolo (2011). International trade in services: A portrait of importers and exporters. Journal of International Economics 84(2), 188206.

Broda, C. and D. E. Weinstein (2006). Globalization and the gains from variety. The Quarterly Journal of Economics 121(2), 541-585.

Crino, R. (2010). Service offshoring and white-collar employment. The Review of Economic Studies $77(2)$, 595-632.

Egger, P., M. Larch, and K. E. Staub (2012). Trade preferences and bilateral trade in goods and services: A structural approach.

Feenstra, R. C., R. E. Lipsey, L. G. Branstetter, C. F. Foley, J. Harrigan, J. B. Jensen, L. Kletzer, C. Mann, P. K. Schott, and G. C. Wright (2010). Report on the state of available data for the study of international trade and foreign direct investment. National Bureau of Economic Research.

Foster, L., J. Haltiwanger, and C. Syverson (2008). Reallocation, firm turnover, and efficiency: Selection on productivity or profitability? American Economic Review 98(1), 394-425.

Francois, J. and B. Hoekman (2010). Services trade and policy. Journal of Economic Literature, 642-692.

Gervais, A. (2014). The impact of policy restrictions on services trade. Mimeo, University of Notre Dame. 
Grossman, G. M. and E. Rossi-Hansberg (2008). Trading tasks: A simple theory of offshoring. American Economic Review, 1978-1997.

Guillaume, G., E. Milet, and D. Mirza (2011). Les firmes francaises dans le commerce de services. Economie et Statistique, 125-147.

Head, K. and T. Mayer (2010). Illusory border effects: distance mismeasurement inflates estimates of home bias in trade. In S. Brakman and P. van Bergeijk (Eds.), The Gravity Model in International Trade: Advances and Applications. Cambridge University Press.

Holmes, T. J. and J. J. Stevens (2012). Exports, borders, distance, and plant size. Journal of International Economics 88(1), 91-103.

Hufbauer, G. C., J. J. Schott, and W. F. Wong (2010). Figuring out the Doha round, Volume 91. Peterson Institute.

Jensen, J. (2011). Global Trade in Services: Fear, Facts, and Offshoring. Peterson Institute for International Economics.

Jensen, J. and L. Kletzer (2006). Tradable Services: Understanding the Scope and Impact of Services Offshoring. In L. Brainard and S. M. Collins (Eds.), Offshoring White-Collar Work, Issues and Implications, Brookings Trade Forum 2005. Brookings Institution Press.

Jensen, J. and L. Kletzer (2010). Measuring Tradable Services and the Task Content of Offshorable Services Jobs. In M. H. Katharine Abraham and J. Spletzer (Eds.), Labor in the New Economy. University of Chicago Press. 
Johnson, K. P. and J. R. Kort (2004). 2004 redefinition of the bea economic areas. Survey of Current Business 84(11), 68-75.

Kelle, M., J. Kleinert, H. Raff, and F. Toubal (2013). Cross-border and foreign affiliate sales of services: Evidence from german microdata. The World Economy 36(11), 1373-1392.

Liu, R. and D. Trefler (2008). Much ado about nothing: American jobs and the rise of service outsourcing to China and India. NBER Working Paper.

Melitz, M. J. (2003). The impact of trade on intra-industry reallocations and aggregate industry productivity. Econometrica 71 (6), 1695-1725.

Moretti, E. (2010). Local multipliers. American Economic Review, 373-377.

van der Marel, E. and B. Shepherd (2013). Services trade, regulation and regional integration: evidence from sectoral data. The World Economy 36(11), 1393-1405.

Wilson, D. J. (2012). Fiscal spending jobs multipliers: Evidence from the 2009 american recovery and reinvestment act. American Economic Journal: Economic Policy 4(3), 251-282.

Yilmazkuday, H. (2012). Understanding interstate trade patterns. Journal of International Economics 86(1), 158-166.

Young, A. (2014). Structural transformation, the mismeasurement of productivity growth, and the cost disease of services. American Economic Review 104 (11), 3635-3667. 
TABLE 1

Most AND LEAST CONCENTRATED MANUFACTURING AND SERVICES INDUSTRIES

\begin{tabular}{llll}
\hline \hline NAICS & Sector & Industry description & SES \\
\hline Panel A: & Most concentrated industries & \\
315111 & Manufacturing & Sheer Hosiery Mills & 0.94 \\
312210 & Manufacturing & Tobacco Stemming and Redrying & 0.93 \\
311311 & Manufacturing & Sugarcane Mills & 0.92 \\
335912 & Manufacturing & Primary Battery Manufacturing & 0.91 \\
325182 & Manufacturing & Carbon Black Manufacturing & 0.91 \\
541360 & Services & Geophysical Surveying and Mapping Services & 0.82 \\
483211 & Services & Inland Water Freight Transportation & 0.82 \\
454112 & Services & Electronic Auctions & 0.82 \\
487990 & Services & Scenic and Sightseeing Transportation, Other & 0.80 \\
522210 & Services & Credit Card Issuing & 0.78 \\
\hline Panel B: & Least concentrated industries & \\
322211 & Manufacturing & Corrugated and Solid Fiber Box Manufacturing & 0.22 \\
327390 & Manufacturing & Other Concrete Product Manufacturing & 0.22 \\
332710 & Manufacturing & Machine Shops & 0.22 \\
323114 & Manufacturing & Quick Printing & 0.19 \\
327320 & Manufacturing & Ready-Mix Concrete Manufacturing & 0.15 \\
453210 & Services & Office Supplies and Stationery Stores & 0.07 \\
445110 & Services & Supermarkets and Other Grocery Stores & 0.07 \\
443112 & Services & Radio, Television, and Other Electronics Stores & 0.07 \\
722110 & Services & Full-Service Restaurants & 0.06 \\
621210 & Services & Offices of Dentists & 0.06 \\
\hline
\end{tabular}

Notes: This table presents the six-digit NAICS code, sector, description and measured share of excess supply $\left(S E S_{s}\right.$ defined in equation $\left.(7)\right)$ for the top 5 most concentrated and least concentrated manufacturing and services industries. The SES ranges from 0 (production equal consumption in all regions) to 1 (production is located in a subset of regions disjoint from the set of regions where consumption takes place). 
TABLE 2

SUMMARY DATA OF SHARE OF EXCESS SUPPLY

\begin{tabular}{llccc}
\hline \hline \multirow{2}{*}{ NAICS } & Sector description & \multicolumn{2}{c}{ Share of excess supply } & \multirow{2}{*}{$\begin{array}{c}\text { Number of } \\
\text { Industries }\end{array}$} \\
\cline { 3 - 4 } & & Mean & S.D. & 463 \\
\hline $31-33$ & Manufacturing & 0.59 & 0.16 & 71 \\
42 & Wholesale trade & 0.39 & 0.13 & 72 \\
$44-45$ & Retail trade & 0.21 & 0.14 & 48 \\
$48-49$ & Transportation & 0.45 & 0.19 & 30 \\
51 & Information & 0.43 & 0.17 & 33 \\
52 & Finance and insurance & 0.44 & 0.19 & 24 \\
53 & Real Estate and leasing & 0.29 & 0.15 & 47 \\
54 & Professional services & 0.32 & 0.14 & 43 \\
56 & Administrative services & 0.28 & 0.12 & 53 \\
$61-62$ & Education and health care & 0.23 & 0.12 & 40 \\
$71-72$ & Recreation and Food Service & 0.35 & 0.18 & 45 \\
81 & Other personal services & 0.25 & 0.11 & 969 \\
& Overall & 0.45 & 0.21 & \\
\hline
\end{tabular}

Notes: For each broad industry group, the table presents the mean and standard deviation across six-digits NAICS industries for the share of excess supply (the measure of disparity between local output and expenditure defined in equation (7)), and the number of six-digits NAICS industry. 
TABLE 3

Summary STATISTICS FOR ESTIMATED TRADE COSTS

\begin{tabular}{|c|c|c|c|}
\hline NAICS & Description & $\widehat{t}_{s}$ & $\mu\left(\widehat{t}_{s}\right)$ \\
\hline $31-33$ & Manufacturing & $\begin{array}{c}0.769 \\
(1.533)\end{array}$ & $\begin{array}{c}0.010 \\
(0.020)\end{array}$ \\
\hline 42 & Wholesale trade & $\begin{array}{c}3.041 \\
(2.516)\end{array}$ & $\begin{array}{c}0.002 \\
(0.006)\end{array}$ \\
\hline $44-45$ & Retail trade & $\begin{array}{c}6.020 \\
(2.836)\end{array}$ & $\begin{array}{c}0.001 \\
(0.005)\end{array}$ \\
\hline $48-49$ & Transportation & $\begin{array}{c}3.224 \\
(3.087)\end{array}$ & $\begin{array}{c}0.002 \\
(0.006)\end{array}$ \\
\hline 51 & Information & $\begin{array}{c}7.774 \\
(10.200)\end{array}$ & $\begin{array}{c}0.005 \\
(0.009)\end{array}$ \\
\hline 52 & Finance and insurance & $\begin{array}{c}5.669 \\
(6.881)\end{array}$ & $\begin{array}{c}0.003 \\
(0.010)\end{array}$ \\
\hline 53 & Real Estate and leasing & $\begin{array}{l}22.050 \\
(7.982)\end{array}$ & $\begin{array}{c}0.049 \\
(0.032)\end{array}$ \\
\hline 54 & Professional services & $\begin{array}{c}4.887 \\
(3.392)\end{array}$ & $\begin{array}{c}0.001 \\
(0.006)\end{array}$ \\
\hline 56 & Administrative services & $\begin{array}{c}4.657 \\
(2.309)\end{array}$ & $\begin{array}{c}0.000 \\
(0.000)\end{array}$ \\
\hline $61-62$ & Education and health care & $\begin{array}{c}3.058 \\
(2.224)\end{array}$ & $\begin{array}{c}0.000 \\
(0.000)\end{array}$ \\
\hline $71-72$ & Recreation and food services & $\begin{array}{c}3.727 \\
(2.360)\end{array}$ & $\begin{array}{c}0.000 \\
(0.002)\end{array}$ \\
\hline \multirow[t]{2}{*}{81} & Other Personal Services & $\begin{array}{c}4.830 \\
(2.488)\end{array}$ & $\begin{array}{c}0.000 \\
(0.001)\end{array}$ \\
\hline & Overall & $\begin{array}{c}3.166 \\
(4.881)\end{array}$ & $\begin{array}{c}0.006 \\
(0.017)\end{array}$ \\
\hline
\end{tabular}

Notes: This table presents results from estimating trade costs separately for each of the 969 six-digits NAICS industries in our sample. For each broad industry group, the table presents the mean and standard deviation across industries for the estimated trade costs and objective function, defined as the square of the difference between the actual and simulated share of excess supply. 
TABLE 4

ESTIMATED TRADE COSTS AND INDICATORS OF TRADABILITY

\begin{tabular}{lc}
\hline \hline & Correlation with trade costs \\
\cline { 2 - 2 } Trade share & -0.31 \\
Average distance shipped & -0.24 \\
Occupation index & -0.13 \\
\hline
\end{tabular}

Notes: This table presents correlations between the estimated trade costs and indicators of tradability. See Appendix for variable definitions and construction. The sample contains the 969 industries included in our sample except for "Average distance shipped" which is available only for 545 (predominantly manufacturing) industries covered in the US Census Bureau's Commodity Flow Survey. 
TABLE 5

DISTRIBUTION OF VALUE ADDED ACROSS INDUSTRY-GROUP AND TRADABILITY

\begin{tabular}{llrcc}
\hline \hline NAICS & Sector description & Total & Non-tradable & Tradable \\
\hline $31-33$ & Manufacturing & 17.3 & 4.6 & 12.7 \\
42 & Wholesale trade & 8.1 & 5.5 & 2.6 \\
$44-45$ & Retail trade & 8.2 & 8.1 & 0.1 \\
$48-49$ & Transportation & 3.5 & 2.7 & 0.9 \\
51 & Information & 6.6 & 5.0 & 1.6 \\
52 & Finance and insurance & 9.4 & 7.4 & 2.0 \\
53 & Real estate and leasing & 17.2 & 17.2 & 0.0 \\
54 & Professional services & 9.1 & 7.9 & 1.2 \\
56 & Administrative services & 4.0 & 3.9 & 0.1 \\
$61-62$ & Education and health care & 9.0 & 8.5 & 0.5 \\
$71-72$ & Recreation and food Services & 4.9 & 4.4 & 0.6 \\
81 & Other personal services & 2.7 & 2.4 & 0.3 \\
& Total & 100.0 & 77.6 & 22.4 \\
\hline
\end{tabular}

Notes: This table presents the distribution of value added across broad industry group and tradability. We classify an industry as tradable if the estimated trade costs for that industry is lower than $t_{75}$, where $t_{75}$ is the trade costs threshold such that 75 percent of manufacturing employment is classified in tradable industries. 
TABLE 6

TRADABLE VS. NON-TRADABLE INDUSTRY CHARACTERISTICS

\begin{tabular}{|c|c|c|}
\hline & Wage & Productivity \\
\hline \multicolumn{3}{|c|}{ Panel A: Across industries } \\
\hline \multirow[t]{2}{*}{ Tradable indicator } & 0.28 & 0.32 \\
\hline & $(0.03)$ & $(0.04)$ \\
\hline$R^{2}$ & 0.10 & 0.06 \\
\hline Observations & 969 & 969 \\
\hline \multicolumn{3}{|c|}{ Panel B: Across industries within broad group } \\
\hline \multirow[t]{2}{*}{ Tradable indicator } & 0.16 & 0.24 \\
\hline & $(0.03)$ & $(0.04)$ \\
\hline$R^{2}$ & 0.38 & 0.46 \\
\hline Observations & 969 & 969 \\
\hline \multicolumn{3}{|c|}{ Panel C: Across industries within broad group, service sector only } \\
\hline \multirow[t]{2}{*}{ Tradable indicator } & 0.28 & 0.26 \\
\hline & $(0.05)$ & $(0.06)$ \\
\hline$R^{2}$ & 0.44 & 0.65 \\
\hline Observations & 506 & 506 \\
\hline
\end{tabular}

Notes: This table presents results from OLS regressions of industrylevel measures of average wages and labor productivity on a variable indicator equal to 1 if the industry is tradable and 0 otherwise. We classify an industry as tradable if the estimated trade costs for that industry is lower than $t_{75}$, where $t_{75}$ is the trade costs threshold such that 75 percent of manufacturing employment is classified in tradable industries. 
TABLE 7

DISTRIBUTION OF GAINS FROM TRADE ACROSS INDUSTRY-GROUP

\begin{tabular}{lll}
\hline \hline NAICS & Sector description & Share \\
\hline $31-33$ & Manufacturing & 0.565 \\
42 & Wholesale trade & 0.116 \\
$44-45$ & Retail trade & 0.005 \\
$48-49$ & Transportation & 0.039 \\
51 & Information & 0.070 \\
52 & Finance and insurance & 0.089 \\
53 & Real Estate and leasing & 0.001 \\
54 & Professional services & 0.051 \\
56 & Administrative services & 0.004 \\
$61-62$ & Education and health care & 0.024 \\
$71-72$ & Recreation and Food Service & 0.025 \\
81 & Other personal services & 0.012 \\
\hline
\end{tabular}

Notes: This table presents the distribution of gains from trade across broad industry group associated with a symmetric liberalization. 

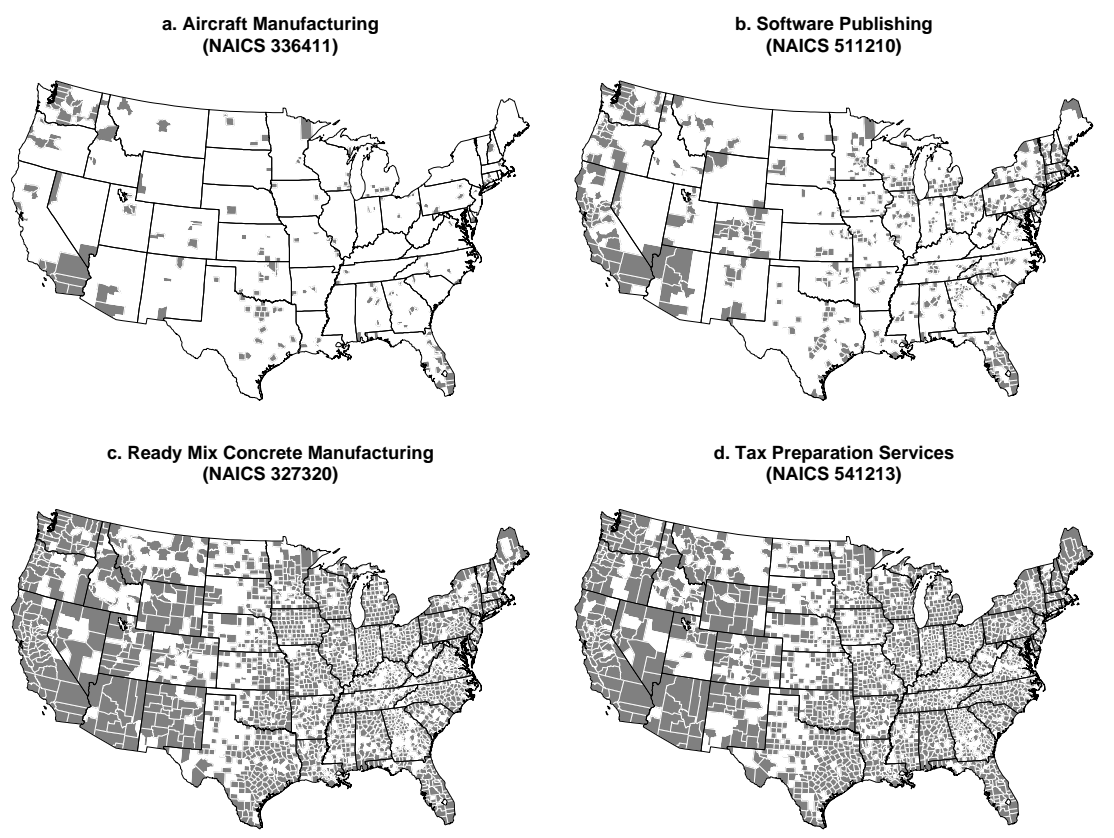

Figure 1: GeOGRAPHical Distribution of IndUStRy EMPlOyMEnT 


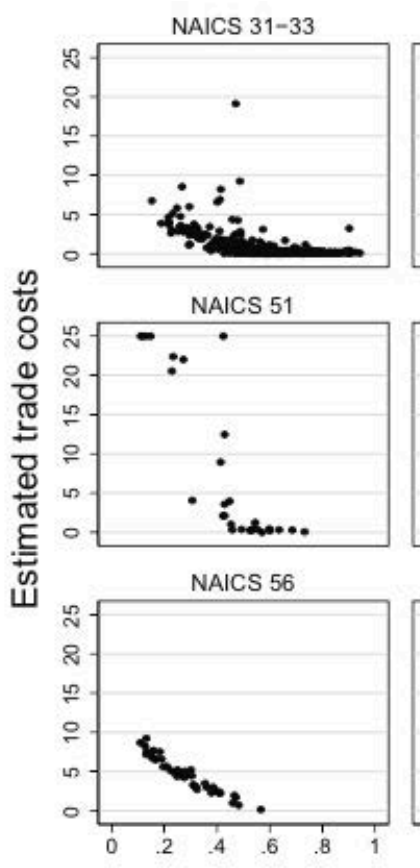

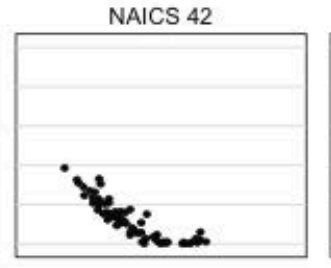

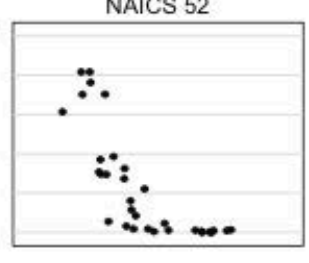

NAICS 61-62

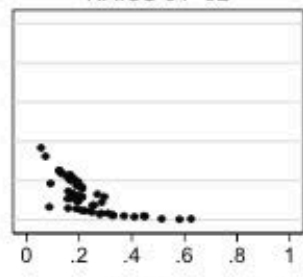

Share of excess supply
NAICS $44-45$

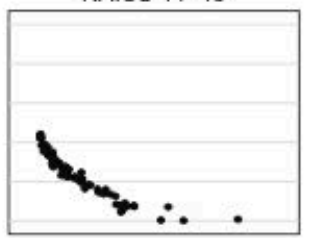

NAICS 53

NAICS $48-49$

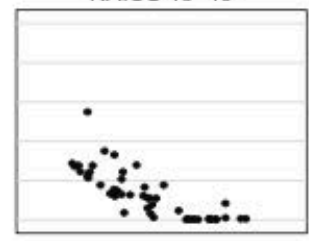

NAICS 54

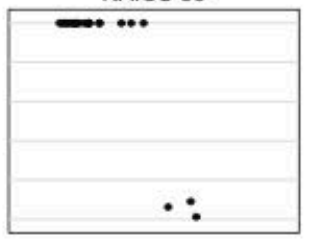

NAICS $71-72$

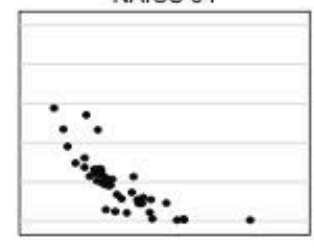

NAICS 81

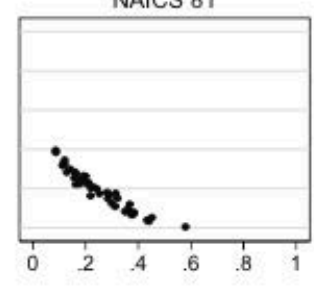

Figure 2: Share of excess supply and estimated trade costs 

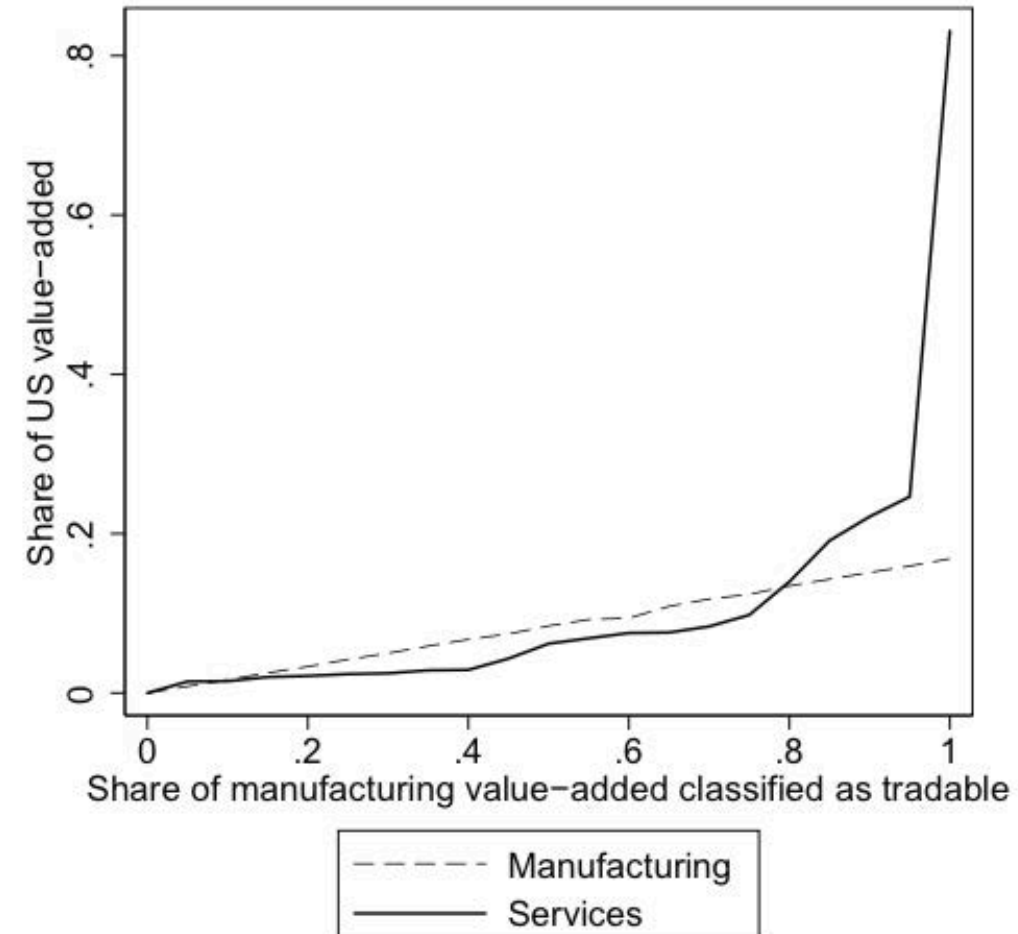

Figure 3: Sectors' share of US value-added in tradable industries 


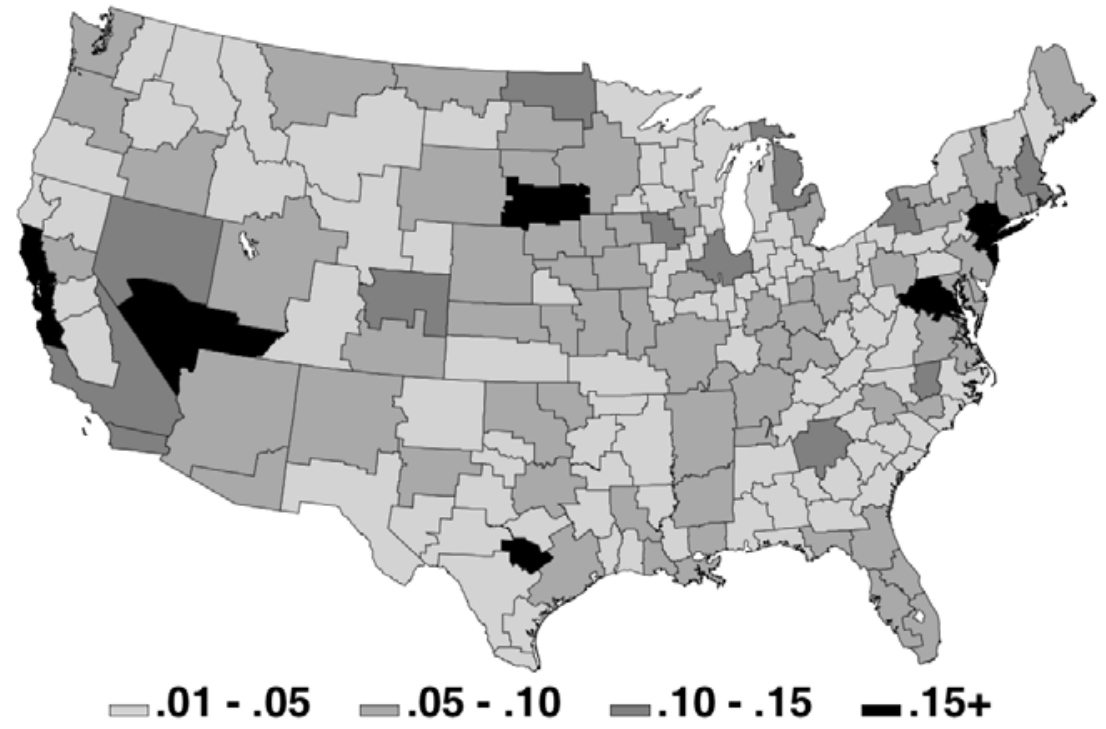

Figure 4: Tradable service industries' share of regional value added 


\section{A Data Appendix - For Online Publication}

In this appendix, we provide additional details on the data, sample and measurement.

\section{A.1 Economic Census}

The Economic Census (EC) is conducted by the US Census Bureau, and firms are required by law to complete the questionnaires they receive. Respondents are asked to provide a range of operational and performance data. The Economic Census is primarily conducted on an establishment basis - a single physical location at which business is conducted, or services or industrial operations are performed. An establishment is not necessarily identical with a firm (or enterprise), which may consist of one or more establishments. A company operating at more than one location is required to file a separate report for each location or establishment. Companies engaged in distinctly different lines of activity at one location are requested to submit separate reports, if the business records permit such a separation, and if the activities are substantial in size. When these conditions are not met, activities at the same location are generally grouped together as a single establishment and the entire establishment is classified on the basis of its primary activity. Business establishments in the EC are grouped into industries based on the similarity of their production processes and classified according to the North American Industry Classification System (NAICS). 
The EC covers the vast majority of the private economy but does not provide information on self-employed individuals, employees of private households, railroads, agricultural production, or most government activities. Specifically, the following NAICS codes are not covered in the economic census: 11 Agriculture, Forestry, Fishing and Hunting; 482 Rail Transportation; 491 Postal Service; 525 Funds, Trusts, and Other Financial Vehicles; 6111 Elementary and Secondary Schools; 6112 Junior Colleges; 6113 Colleges, Universities, and Professional Schools; 8131 Religious Organizations; 81393 Labor Unions and Similar Labor Organizations; 81394 Political Organizations; 814 Private Households; 92 Public Administration. In addition, the economic census does not generally include government-owned establishments, even when their primary activity would be classified in industries covered by the economic census. ${ }^{18}$

We make use of the detailed, county-level geographical information on the EC records, industrial classification information, revenue, and employment data to construct region-industry measures of supply and demand. Establishments are assigned to regions that are the Economic Areas (EA) defined by the Bureau of Economic Analysis (BEA) as described in Johnson and Kort (2004). Industries are defined at the six-digit NAICS level.

\section{Revenue}

For each region-industry, we measure total revenue (supply) by taking the sum

of revenue over all plants in an industry $s$ in a region $j$ so that $R_{j s}=\sum_{k=1}^{N_{j}} r_{j s k}$

18. See http://www.census.gov/econ/census/help/naics_other_classification_systems/codes_not_covered.html for more information. 
where $r_{j k}$ is the revenue of the $k^{t h}$ plant in region $j$. In the estimation, we use the region's share of industry supply as the measure of revenue.

The data do not contain information on region-level exports for all industries that can be used to adjust supply to account for international trade. Instead, we assume that exports are distributed across regions according to production. In other words, a region that produces 10 percent of output in an industry is assumed to also account for 10 percent of US exports in that industry. To examine the implications of this assumption, we produced the revenue share for each region-industry in the manufacturing sector, where direct export information is available, adjusting for direct exports and compared this to the region-industry measure constructed using the proportional adjustment. The correlation between direct export adjustment and the proportional adjustment of industry revenue is 0.98 in the manufacturing sector. This suggests that the measurement error associated with assuming international trade is distributed proportionally with output is generally small.

\section{Expenditure}

For each region-industry, we measure total expenditure (demand) using information on the industrial composition of the region from the $\mathrm{EC}$ and the 2007 American Community Survey for industries out of scope for the EC and information on each industry's use of all inputs from the BEA's Detailed InputOutput Use table for 2007. Specifically, our measure of industry s's demand in region $i$ is defined as:

$$
E_{s i}=\left(\sum_{t} s_{s t}^{I O} \cdot s_{i t}^{D}\right) R_{s}
$$


where $s_{s t}^{I O}$ represents the share of industry $s$ output demanded by each industry $t$, for all $t=1, \ldots, T$ ( $T$ includes all industries in the private sector, investment, government, and final demand), $s_{i t}^{D}$ represents the share of industry demand measures by the share of employment or, in the case of final demand, share of total income from the 2007 American Community Survey in region $i$, and $R_{s}$ is aggregate revenue in industry $s .{ }^{19}$ Because we do not know the distribution of investment demand across industries, we use final demand to represent the geographical distribution of investment demand. The term in parentheses gives the adjusted share of demand for industry $s$ in region $i$. Multiplying this term by total revenue in the industry gives expenditure in regions $i$. In the estimation, we use the region's share of total industry demand as the measure of expenditure.

A measurement issue we face is that some region-industry demand is served by imports, so region-industry demand would be overstated without adjusting for imports. The EC data do not have direct information on imports of intermediate products. Instead, we use information from BEA's supplemental Import Matrix to adjust demand for imported inputs. The Import Matrix provides estimates of imports by industry by commodity using the import comparability assumption. ${ }^{20}$ We match the Import Matrix to the Input-Output table and adjust demand by imports.

19. We use the location of employment instead of revenue because we include demand from sectors where revenue information are not reliable (Management of Companies and Enterprises (NAICS 55)) or industries outside the scope of the EC (e.g. federal, state, and local government, Postal Service, Education, Agriculture (NAICS 1)).

20. See Feenstra and Jensen (2012) for a discussion of the import comparability assumption. 


\section{Production costs}

The revenue-based labor productivity for region $j$ industry $s$ equals its revenue in the industry per unit of labor employed

$$
\theta_{j s} \equiv \frac{r_{j s}}{l_{j s}}
$$

Regional revenue in an industry can be computed from equation (5) by taking the sum of bilateral sales across all destinations

$$
r_{j s}=\sum_{i} r_{i j s}=\left(\frac{\sigma_{s}}{\sigma_{s}-1}\right)^{1-\sigma_{s}}\left(\frac{w_{j}}{z_{j s}}\right)^{1-\sigma_{s}} A_{j s}
$$

where $A_{j s}=\sum_{i} E_{i s} P_{i s}^{\sigma_{s}-1} \tau_{\text {ins }}^{1-\sigma_{s}}$ is the region-industry market access term, a measure of aggregate demand. From the total cost function (3), labor per region is

$$
l_{j s}=F_{s}+\frac{q_{j s}}{z_{j s}} \quad \text { with } \quad q_{j s}=\sum_{i} \tau_{i j s} q_{i j s}=\left(\frac{\sigma_{s}}{\sigma_{s}-1}\right)^{-\sigma_{s}}\left(\frac{w_{j}}{z_{j s}}\right)^{-\sigma_{s}} A_{j s} .
$$

Substituting equations (19) and (20) into (18) yields

$$
\theta_{j s}=\left(\frac{\sigma_{s}}{\sigma_{s}-1}\right)\left(1-\frac{F_{s}}{l_{j s}}\right) w_{j}
$$

where we have used $q_{j s}=\left(l_{j s}-F_{s}\right) z_{j s}$.

Using $q_{j s}$, defined in (20), in the definition of labor per firm, we get

$$
l_{j s}=F_{s}+\left(\frac{\sigma_{s}-1}{\sigma_{s}}\right)^{\sigma_{s}} \frac{A_{j s} z_{j s}^{\sigma_{s}-1}}{w_{j}^{\sigma_{s}}}
$$


Substituting this result into equation (21), we get

$$
\theta_{j s}=\left(\frac{\sigma_{s}}{\sigma_{s}-1}\right)\left[1-\frac{1}{1+\left(\frac{\sigma_{s}-1}{\sigma_{s}}\right)^{\sigma_{s}} \frac{A_{j s} z_{j s}^{\sigma_{s}-1}}{F_{s} w_{j}^{\sigma_{s}}}}\right] w_{j}
$$

Our measure of $\lambda$ is defined as the ratio of revenue-based labor productivity to wage (i.e., $\theta_{j s} / w_{j}$ ). Equation (23) shows that this measure is positively correlated with region-industry technical efficiency $\left(z_{j s}\right)$ but also captures variation in the elasticity of demand across industry as well as variation in fixed production costs across industry-region.

\section{Summary Statistics}

Table A1 reports descriptive statistics for the measures used in our estimation. Because we use shares of $R$ and $E$ in the estimation, we do not report the simple mean and standard deviation. Instead, we calculate the standard deviation across regions within an industry and present the mean and standard deviation across industries of the industry-level measures of standard deviation for $R, E$, and $\lambda$. Table A1 shows that there is significantly more concentration in supply than demand across regions. The mean standard deviation of $R$ across regions within industries is 1.80 , while the measure for $E$ is 0.94 . The higher level of variation in $R$ suggests that identification of trade costs is coming primarily through $R$. This is reassuring as $R$ is well measured.

\section{[ TABLE A1 HERE ]}




\section{Value Added}

The EC data contain sales, but not value added measures. We compute the share of value added in each industry using value added (GDP) information from BEA's IO Tables 2007. For BEA commodities for which there are multiple six-digit NAICS codes, we allocate value added based on the share of payroll in each six-digit NAICS industry within the commodity category. We use the share of payroll rather than sales because the BEA commodity codes are particularly aggregated in wholesale and retail trade, where payroll is likely to be more correlated with value added than sales.

\section{Sample construction}

There are about one thousand six-digit NAICS industry classifications. ${ }^{21} \mathrm{We}$ retain all industries from the EC while developing the supply and demand measures. However, we do not report analytical results for all industries. We exclude Mining (NAICS 21) and Utilities (NAICS 22) because many of the industries in these sectors have small numbers of producers and, as a result, do not meet the disclosure release protocols of the US Census Bureau. We exclude Construction (NAICS 23) because the unit of analysis is not consistent with the other EC data. We exclude Management of Companies (NAICS 55 ) because there is no reliable revenue data and we cannot produce the productivity estimates required for estimating trade costs. We lose an additional 21 industries across the Manufacturing (NAICS 30), Retail (NAICS 44-45), Transportation and Warehousing (NAICS 48-49), Information (NAICS 51),

21. See http://www.census.gov/eos/www/naics/ for more information. 
Finance and Insurance (NAICS 52), and Administrative Support and Waste Remediation (NAICS 56) sectors due to disclosure prevention protocols. Our final analytical sample includes 969 six-digit NAICS industries.

\section{A.2 Measuring the elasticity of demand}

Estimates of the elasticity of demand for services industries are not readily available, so we construct elasticity of demand measures for all industries. From our theoretical model, the price elasticity of demand is defined as $\widehat{\sigma}_{s}=R_{s} / G_{s}$ ), where $G_{s}$ denotes gross operating surplus (see equation (12). We use this results and BEA data on gross operating surplus and value added to estimate the price elasticity of demand for each of the roughly 70 industries (approximately three-digit NAICS) for which information is available. ${ }^{22}$ We divide value added GDP (our measure of $R_{s}$ ) by gross operating surplus (a proxy for $G_{s}$ ) for each industry for years 1998 - 2012. Gross operating surplus is a residual for most industries constructed by subtracting total intermediate inputs, compensation of employees, and taxes on production and imports less subsidies from total industry output. However, it includes consumption of fixed capital, proprietors' income, and corporate profits and therefore provides a reasonable approximation to $G_{s}$. We take the median across year for each industry to obtain a measure of central tendency robust to outliers.

Table A2 report the mean and standard deviation across industry for each broad industry group. The results for manufacturing are in line with estimates provided in the literature. For instance, Broda and Weinstein (2006) uses trade

22. See www.bea.gov/industry/gdpbyind_data.htm for more information on these data. 
flows to estimate the price elasticity of demand and report means ranging from 4.0 to 17.3 depending on the time period and level of aggregation used in the estimation. An advantage of our approach is that we obtain estimates comparable across all sectors of the economy. Expect for "Education and health care", the mean and median estimated elasticity of demand is lower on average in services industries than in manufacturing industries. This indicates that consumers are less sensitive to variation in prices in services industry which, according to our model, indicates output is less differentiated in those industries.

\section{[ TABLE A2 HERE ]}

Our estimates vary at subsector-level. We experimented with the most disaggregated data available, input-output commodity level data (approximately six-digit NAICS). The estimates of $\sigma$ derived from the more detailed commoditylevel data had much higher variance than those at the 3-digit level. In particular, we obtain estimates smaller than 1 and some negative values. Because our model does not accommodate $\sigma$ s below 1, we could not estimate trade costs for these industries. However, the main empirical results (presented in section 6) are robust to using the more detailed $\sigma$ estimates.

\section{A.3 Measures of Tradability}

In this section, we describe the construction of measures of tradability to which we compare our trade costs measures. 


\section{Trade Share}

We use data from BEA's Detailed Input-Output Use Table to construct a measure of trade exposure at the BEA commodity level. The measure of trade exposure we construct to compare to our estimates of trade costs is:

$$
\text { Trade Exposure }=\frac{\text { IMP }}{\text { Absorbtion }}+\frac{\text { EXP }}{\text { Production }}
$$

where Absorbtion $=$ Output + IMP - EXP, IMP denotes imports, and EXP is exports. We note that BEA produces import estimates for approximately 100 service sector commodities (industries), even though the underlying data collection instrument contains only between 17 and 30 categories of services trade. In addition, as described above, these estimates are developed using the "import comparability" assumption. BEA uses estimation and imputation methods to allocate the services trade measured in their survey programs across the detailed commodity categories in the input-output tables. For the service sector, because of the allocation from around 20 service trade categories across 100 service industries, these estimates might differ substantially from actual trade. In addition, there are more service industries in our sample (approximately 400) than in the BEA input-output tables (approximately 100). This might also introduce noise in the correlations.

\section{Distance Shipped}

The Commodity Flow Survey (CFS) produces data on the movement of goods in the United States. It provides information on commodities shipped, their 
value, weight, and mode of transportation, as well as the origin and destination of shipments of commodities from manufacturing, mining, wholesale, and select retail and services establishments - namely, electronic shopping and mail-order houses, fuel dealers, and publishers (including newspaper, periodical, book, directory, and music publishers). Additionally, the survey covers auxiliary establishments (i.e., warehouses and managing offices) of multi-establishment companies. The survey does not cover establishments classified in transportation, construction, and most retail and services industries. Farms, fisheries, foreign establishments, and most government-owned establishments are also excluded.

We use confidential, respondent-level data from the CFS to construct weighted average distance shipped measures (using the same methodology as those published by the CFS program at the three-digit NAICS level) for each six-digit NAICS industry for which data are collected.

\section{Occupation-Based index}

For each of hundreds of occupations, the $\mathrm{O}^{*}$ Net database contains detailed qualitative information on job tasks, work activities (interacting with computers, processing information), and work context (face-to-face discussions, work with others, work outdoors). We use this information to construct an index to compare to our estimated trade costs. To obtain comparable measures across all industries, we use the tradability index developed by Jensen and Kletzer (2010) and then weight each occupation's index by that occupation's share of total employment in an industry to obtain a 4-digit NAICS level industry 
measure of tradability

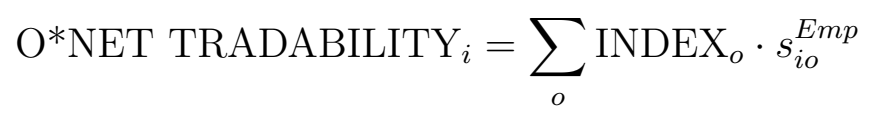

where $I N D E X_{o}$ is the occupation tradability index developed by Jensen and Kletzer (2010) and $s_{i o}^{E m p}$ is the share of industry $i$ employment in occupation $o$. In comparison, Crino (2010) constructs tradability measures for "white-collars" occupations only. 
TABLE A1

SUMMARY STATISTICS FOR REGION-INDUSTRY VARIABLES

\begin{tabular}{lccc}
\hline \hline & Expenditure $(E)$ & Revenue $(R)$ & Costs $(\lambda)$ \\
\hline Mean & 0.94 & 1.80 & 0.22 \\
S.D. & 0.14 & 0.90 & 0.51 \\
\hline \multicolumn{4}{c}{ Correlations } \\
$E$ & 1.00 & 1.00 & \\
$R$ & 0.54 & 0.12 & 1.00 \\
$\lambda$ & 0.04 & & \\
\hline
\end{tabular}

Notes: This table presents the mean and standard deviation across industries of the standard deviation across regions for expenditure, revenue and our measure of $\lambda$. The table also presents the correlations between the region-industry measures. The sample contains 177,327 industry-regions across 969 industries. 
TABLE A2

ESTIMATES FOR THE ELASTICITY OF DEMAND

\begin{tabular}{llccc}
\hline \hline NAICS & Sector description & Mean & Median & S.D. \\
\hline $31-33$ & Manufacturing & 8.14 & 7.52 & 2.87 \\
42 & Wholesale trade & 5.17 & 5.17 & - \\
$44-45$ & Retail trade & 6.31 & 6.31 & - \\
$48-49$ & Transportation & 6.35 & 6.18 & 2.18 \\
51 & Information & 3.02 & 3.12 & 0.18 \\
52 & Finance and insurance & 5.91 & 4.31 & 3.41 \\
53 & Real estate and leasing & 1.90 & 2.06 & 0.22 \\
54 & Professional services & 5.60 & 5.24 & 1.92 \\
56 & Administrative services & 5.98 & 6.16 & 0.34 \\
$61-62$ & Education and health care & 12.17 & 9.46 & 5.57 \\
$71-72$ & Recreation and food Services & 6.09 & 5.27 & 1.84 \\
81 & Other personal services & 6.23 & 6.23 & - \\
& All industries & 7.14 & 6.31 & 3.20 \\
\hline
\end{tabular}

Notes: This table presents the mean, median and standard deviation across industries within broad groups for the estimated elasticity of demand. 